\title{
Diş Hekimlerine Yönelik Şiddet: Bir Anket Çalışması
}

\author{
Violence Towards Dentists: A Survey Questionnaire
}

\author{
Beytullah Karadayl ${ }^{l}$,Ende Varlık Tokgözoğlu ${ }^{l}$, Ibrahim Eray Çakı ${ }^{1}$, Mehmet Altınok ${ }^{l}$, \\ Ahsen Kaya ${ }^{2}$, Hüseyin Afşin ${ }^{3}$, Abdi Özaslan ${ }^{1}$ \\ ${ }^{1}$ Ístanbul Üniversitesi, Cerrahpaşa Tıp Fakültesi, Adli Tıp Anabilim Dalı, İstanbul \\ ${ }^{2}$ Ege Üniversitesi, Tip Fakültesi, Adli Tip Anabilim Dalı, İzmir \\ ${ }^{3}$ Adli Tıp Kurumu Başkanlığı, İstanbul
}

\section{Özet}

Amaç: Bu çalışmanın iki amacı vardır. Birincisi ağız ve diş sağlığ tanı ve tedavi birimlerinde çalışan diş hekimlerinin maruz kaldıkları ve tanık oldukları şiddetin niteliklerinin belirlenmesidir. İkincisi ise yaşanan şiddet olayı sonrasındaki sürecin ortaya konulmasidir.

Gereç ve Yöntem: 1 Temmuz 2014 - 31 Aralık 2014 tarihleri arasında İstanbul'daki kamuya ait ağız ve diş sağlığı merkezleri ile üniversitelerin diş hekimliği fakültelerinde görev yapan diş hekimlerine yönelik bir anket çalışması yapıldı. Anket formu üç bölümden oluşturuldu. Birinci bölümde demografik veriler, ikinci bölümde şiddetin sebepleri ve şiddetin önlenmesine yönelik alınabilecek önlemler, üçüncü bölümde ise maruz kalınan şiddetin niteliklerinin belirlenmesine yönelik sorular bulunmaktadır.

Bulgular: Katılımcıların \%48.5'i (n=32) tüm meslek hayatları boyunca en az bir kere şiddete maruz kaldığını, şiddete maruz kaldığını belirtenlerin \%65.6'sının $(n=21)$ da son bir yıl içinde şiddetle karşılaştığı saptandı. Maruz kaldıkları şiddet türü sorgulandığında, \% 71.9'u (n=23) sadece sözel, \%18.7'si (n=6) ise hem sözel hem de fiziksel şiddete maruz kaldıklarını belirtti. Toplumda şiddet vakalarının arttığına inananların oranı \%95.5 $(n=63)$ bulundu. Anket çalışması yapılan kurumda şiddet vakalarının arttığına inananların oranı \%69.7 $(\mathrm{n}=46)$ ve şiddetin engellenebileceğini düşünenlerin oranı ise \% $86.4(n=57)$ olarak belirlendi.

Sonuç: Çalışma küçük bir grubun bu konudaki görüşlerini yansıtmakla birlikte diş hekimlerinin de sağlık alanındaki şiddetten etkilendiğini göstermektedir.

Anahtar Kelimeler: Diş hekimi; Fiziksel şiddet; Sözel şiddet; Şiddet.

\section{Giriş}

İngilizce "agression" kelimesinin Türkçe karşıllı̆ı olan "saldırganlık” kavramı kısaca, bilinçli olarak yapılan

Sorumlu Yazar: Ibrahim Eray Çakı

İstanbul Üniversitesi, Cerrahpaşa Tip Fakültesi,

Adli Tip Anabilim Dall, İstanbul

E-mail: ibrahimeraycaki@gmail.com

Geliş: 29.02.2016 Düzeltme: 13.04.2016 Kabul: 02.05.2016

\section{Abstract}

Objective: This study is aimed to determine the characteristics of the violence that dentists, who work at oral and dental health diagnosis and treatment centers, are exposed to and witness. The study also investigates the process that occurs after the incident.

Materials and Method: A survey was conducted between July 1st and December 31st of 2014 among dentists who work at dental healthcare centers and faculties of dentistry in Istanbul. The survey consists of 3 sections. The sections are structured as followed: Section I, demographical information; Section II, the reasons and possible precautions; Section III, characteristics of the violence.

Results: $48.5 \%(n=32)$ of the participants claimed that they were exposed to some kind of violence at least once in their professional lives. $65.6 \%(\mathrm{n}=21)$ of them were exposed to a violent act in the past year. $71.9 \%(n=23)$ of these exposures were only verbal and $18.7 \%(n=6)$ included both verbal and physical violence. $95.5 \%(n=63)$ of the participants stated that there was a general increase in violent acts in society and $69.7 \%(n=46)$ stated that violent incidents increased in the work place. The study also showed that $86.4 \%(n=57)$ of the participants thought that the violence could have been prevented.

Conclusion: Even though this study reflects the opinions of a small group, it shows that dentists are affected by the violence in the healthcare field.

Keywords: Dentist; Physical violence; Verbal violence; Violence.

ve başkalarını incitebilecek her türlü davranış olarak tanımlanmaktadır (1). Kişilerin saldırgan davranışları kendi isteklerini zorla yaptırma çabası içinde gerçekleştirmeleri olarak ifade edilen şiddet olgusu ise çağımızın önemli bir problemi olup, evde, okulda, iş yerinde, kısacası yaşamın her alanında kendisini göstermektedir.

İş yerindeki şiddet; yaygınlığg, kapsamı ve sonuçları nedeni ile ayrı bir ilgi konusudur (2). Kişisel ve top- 
lumsal hayat ile çalışma hayatı üzerindeki olumsuz ciddi etkileri, bu konuya ilginin artmasında etkili olmaktadır. Bu kapsamda uluslararası çalışmalar da yapılarak çözüm önerileri geliştirilmeye çalışılmaktadır. Bu çalışmalardan biri olan "Issyerinde Şiddet ve Stresten Korunma Rehberi" 2011 yılında Birleşmiş Milletler Kalkınma Programı (UNDP) ve Uluslararası Çalışma Örgütü (ILO) tarafından desteklenerek hazırlanmıştır (3). Bu rehbere göre işyerinde şiddet, "çalışanların işle ilgili ortamlarda saldırı, istismar, tehdit ve diğer şiddet davranışlarına maruz kalmaları" olarak tanımlanmıştır (3). İş yerinde şiddetin, başta hizmet iş kollarında olmak üzere arttığı bildirilmektedir (4). Hizmet iş kolları içerisinde de sağlık alanında çalışanlar şiddete maruz kalma açısından yüksek riskli gruplardan biri olarak değerlendirilmekte olup, bu alandaki şiddetin tüm iş yeri şiddet olaylarının yaklaşık 1/4'ünü oluşturduğu belirtilmektedir (5-7).

Son yıllarda gerek yazilı, gerekse görsel basında hekimler ve diş hekimlerine yönelik şiddet haberleri ile sıklıkla karşılaşılmaktadır. Bu konu ile ilgili yapılan literatür taramasında; çalışmaların büyük bir kısmının hekimler açısından bakıldığında, tıp kökenli hekimler ile ilgili olduğu ve diş hekimlerine yönelik şiddetin özelliklerinin incelendiği çalışma sayısının oldukça az olduğu görülmektedir (6).

$\mathrm{Bu}$ çalışmada, kamudaki ağız ve diş sağlığ tanı ve tedavi birimlerinde çalışan diş hekimlerinin maruz kaldıkları ve tanık oldukları şiddetin özelliklerinin belirlenmesi ile yaşanan şiddet olayı sonrasındaki sürecin ortaya konulması amaçlanmıştır.

\section{Gereç ve Yöntem}

Çalışma 1 Temmuz 2014 - 31 Aralık 2014 tarihleri arasında İstanbul'daki kamuya ait ağız ve diş sağlığı merkezleri ile üniversitelerin diş hekimliği fakültelerinde görev yapan diş hekimleri ile yapıldı. Belirtilen tarihler arasında farklı merkezlere gidilerek diş hekimleriyle yüz yüze görüşüldü ve gönüllü katılımcılara 20 sorudan oluşan "İstanbul'daki Diş Hekimlerine Yönelik Şiddet ve Özellikleri” başlıklı anket hakkında bilgi verildi. Yüz yüze anket uygulaması ile mükerrer katılım önlendi. Anket hakkında bilgi verilen diş hekimlerinden 66'sı ankete katılmayı kabul etti. Türk Diş Hekimleri Birliği'nin 2013 yılında yayınladığı ayrıntılı verilere göre Türkiye'deki diş hekimi sayısının 26,688 olduğu ve bunun da 11,486; sının kamuda çalıştığı bildirilmiştir (8). İstanbul〉da görev yapan 8,216 diş hekiminin ise 1,519 ‘u kamuda çalışmaktadır (8). Bu anket kapsamında hedef kitleden ulaşılan diş hekimi sayıs1 $\% 4.34$ düzeyindedir.

Anket formundaki ilk 3 soruda yaş, cinsiyet, meslek, meslekteki çalışma süresini içeren kişisel bilgiler, sonra- ki 9 soruda çalışılan yer ile ilgili fiziksel şartlar, şiddetin sebeplerine yönelik bilgiler ve şiddetin önlenmesine yönelik alınabilecek önlemler araştırıldı. Anket formlarında yer alan 13. ve 20. sorular arasında ise maruz kal1nan şiddetin özelliklerinin belirlenmesine yönelik sorular soruldu. Verilen yanıtlar bilgisayar ortamında IBM SPSS Statistics for Windows, Version 21.0. Armonk, NY: IBM Corp. programı kullanılarak tanımlayıcı istatistik ve grafik analizi ile değerlendirildi.

\section{Bulgular}

Ankete katılan 66 diş hekimin 26's1 (\%39.4) erkek ve 40 ' 1 (\%60.6) kadındı. Yaş ortalaması ise $33.21 \pm 8.24$ olup, minimum yaş 24 , maksimum yaş 64 , medyan değer 30 'du.

Katılımcıların mesleki eğitim durumlarına göre dağılımlarına bakıldığında; \%48.5'inin ( $\mathrm{n}=32)$ eğitiminin lisans düzeyinde olduğu ve \%51.5'inin de (n=34) Uzman/ Doktora düzeyinde eğitim aldığı belirlendi.

Çalışma kapsamında anketi değerlendirmeye alınan diş hekimlerinin, meslekte ortalama $9.32 \pm 7.48$ yıl çalışmış olduğu, minimum 1 yıl, maksimum 35 yıldır bu mesleği yaptıkları, medyan değerin 7 olduğu tespit edildi (Şekil 1).

Tüm katılımcıların \%48.5'i ( $\mathrm{n}=32)$ meslek hayatları boyunca en az bir kere şiddete maruz kaldığını, şiddete maruz kaldığını belirtenlerin \%65.6'sının $(\mathrm{n}=21)$ da son bir yıl içinde şiddetle karşılaştığı saptandı (Tablo 1).

Erkek katılımcıların meslek hayatları boyunca \%42.3'ünün $(\mathrm{n}=11)$ en az bir kere şiddete maruz kald1ğ1; kadın katılımcılarda bu oranın $\% 52.5(n=21)$ olduğu saptand.

Katılımcılara maruz kaldıkları şiddet türleri sorularak, birden fazla şı işaretleyebilecekleri belirtildi. En sık olarak sözel şiddete maruz kaldıkları saptandı (Tablo 2).

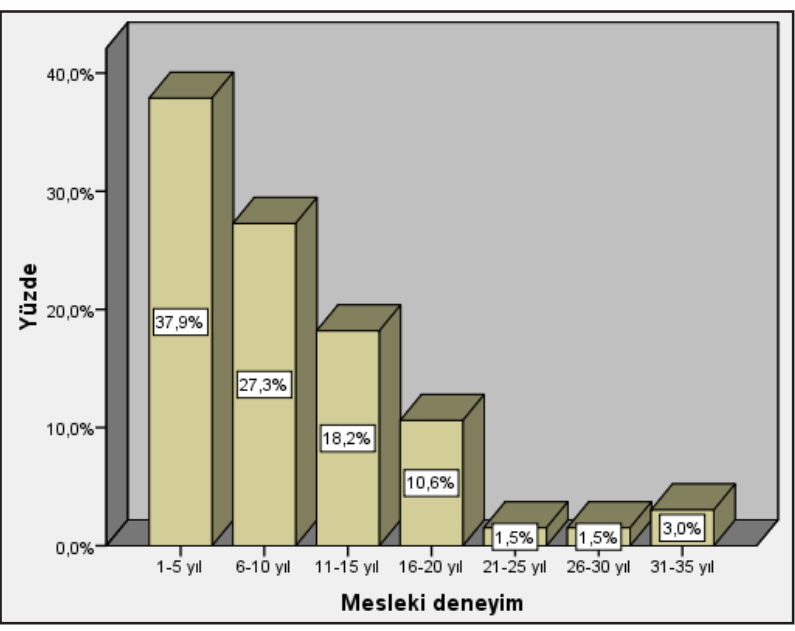

Şekil 1. Katılımcıların diş hekimi olarak çalışma süreleri. 


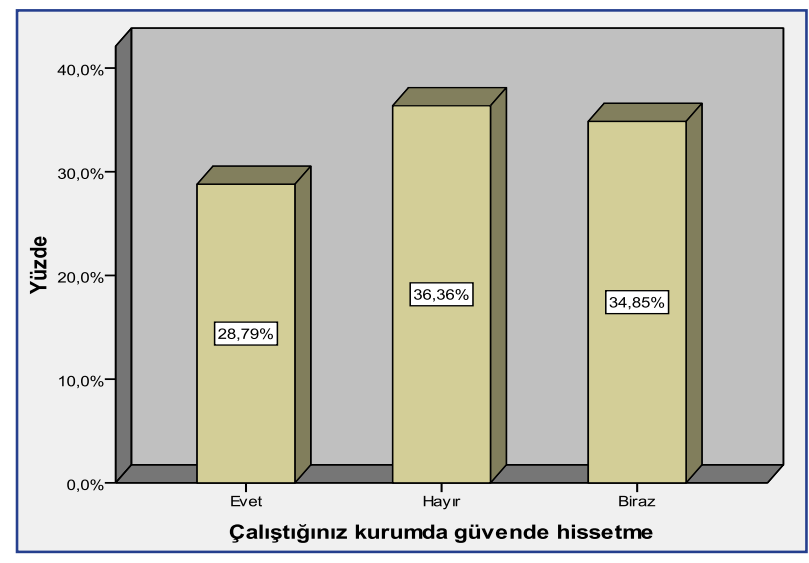

Şekil 2. Katılımcıların 'Çalıştığınız kurumda kendinizi güvende hissediyor musunuz?" sorusuna verdikleri cevapların dağılımı.

Tablo 1. Katılımcıların meslek hayatları boyunca ve son bir yıl içinde şiddete maruz kalma durumları.

\begin{tabular}{|l|l|l|l|l|}
\hline \multirow{2}{\text{Siddete}}{$\begin{array}{l}\text { lidaruz kalma } \\
\text { durumu }\end{array}$} & \multicolumn{2}{|c|}{$\begin{array}{c}\text { Son bir yıl } \\
\text { içinde }\end{array}$} & \multicolumn{2}{c|}{$\begin{array}{c}\text { Meslek hayatı } \\
\text { boyunca }\end{array}$} \\
\cline { 2 - 5 } & n & $\%$ & n & $\%$ \\
\hline $\begin{array}{l}\text { Şiddete maruz } \\
\text { kalmadım }\end{array}$ & 11 & 34,4 & 34 & 51,5 \\
\hline $\begin{array}{l}\text { Şiddete maruz } \\
\text { kaldım }\end{array}$ & 21 & 65,6 & 32 & 48,5 \\
\hline Toplam & 32 & 100,0 & 66 & 100,0 \\
\hline
\end{tabular}

Tablo 2. Katılımcıların maruz kaldıkları şiddet türleri.

\begin{tabular}{|l|l|l|}
\hline Maruz kalınan şiddet türleri & Sayı (n) & Yüzde (\%) \\
\hline Sadece sözel şiddet & 23 & 71,9 \\
\hline Hem sözel, hem de fiziksel şiddet & 6 & 18,7 \\
\hline Sadece fiziksel şiddet & 2 & 6,2 \\
\hline Sözel, fiziksel ve cinsel şiddet & 1 & 3,2 \\
\hline Toplam & 32 & 100,0 \\
\hline
\end{tabular}

Tablo 3. Katılımcıların yaşadıkları şiddet içerikli olaylarda saldırganın özelliği.

\begin{tabular}{|l|l|l|}
\hline Saldırgan & Sayı $(\mathrm{n})$ & Yüzde $(\%)$ \\
\hline Hasta & 18 & 56,2 \\
\hline Hasta yakını & 7 & 21,9 \\
\hline Hasta ve hasta yakını & 7 & 21,9 \\
\hline Toplam & 32 & 100,0 \\
\hline
\end{tabular}

Katılımcıların maruz kaldıkları şiddet türü sorgulandığında, \%71.9'u (n=23) sadece sözel, \%18.7'si (n=6) ise hem sözel hem de fiziksel şiddete maruz kaldıklarını belirtti.

Katılımcıların maruz kaldığı şiddet olayında saldırganın kim olduğu sorgulandı ve şiddetin \%56.2 oranında

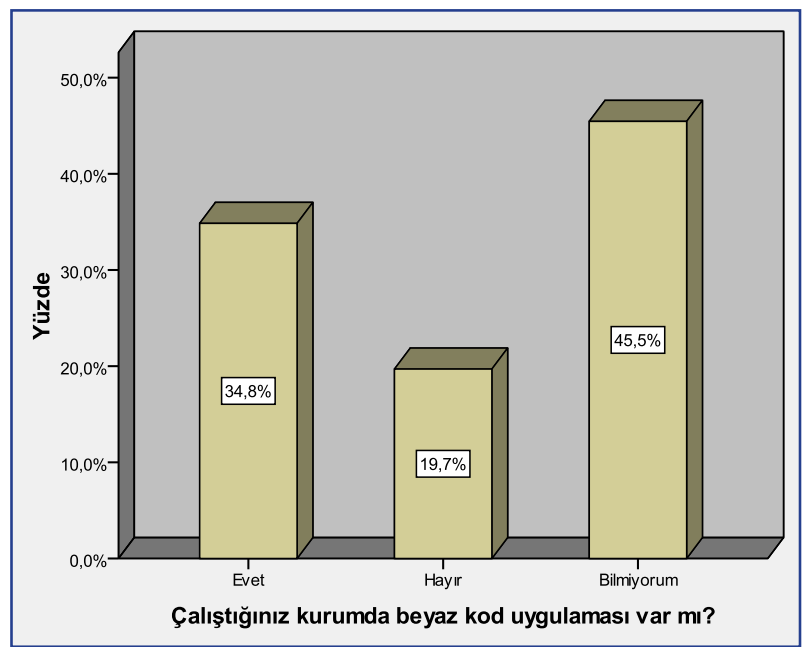

Şekil 3. Katılımcıların ' Çalıştığınız kurumda beyaz kod uygulaması var mı?" sorusuna verdikleri cevapların dağılımı.

hasta tarafindan meydana getirildiği saptandı (Tablo 3). Şiddet olaylarında; saldırıların \%62.5'inin ( $\mathrm{n}=20)$ erkekler, \%15.6'sinin ( $n=5)$ kadınlar ve \%21.9'unun ( $n=7$ ) hem erkekler hem de kadınlar tarafindan birlikte meydana getirildiği gözlendi.

Katılımcıların \%36.4'ü (n=24) ' Çalıştığınız kurumda kendinizi güvende hissediyor musunuz?" sorusuna hayır cevabını vermişlerdir (Şekil 2). Bu soruya verilen yanıtlar cinsiyet göz önüne alınarak değerlendirildiğinde; kadınların \%32,5'inin ( $\mathrm{n}=13)$, erkeklerin \%42,3'ünün $(\mathrm{n}=11)$ "hayır" cevabı verdiği görüldü. "'Çalıştığınız kurumda beyaz kod uygulaması var mı?" sorusuna ise \%45.5 $(n=30)$ oranında "bilmiyorum" yanıtı alınmıştır (Şekil 3).

Katılımcılardan toplumda şiddet vakalarının arttığına inananların oranı $\% 95.5(\mathrm{n}=63)$, çalışılan kurumda şiddet vakalarının arttığına inananların oranı \%69.7 $(\mathrm{n}=46)$ ve şiddetin engellenebileceğini düşünenlerin oranı ise $\% 86.4$ $(n=57)$ olarak belirlendi. Cinsiyet göz önüne alındığında alınacak önlemler ile şiddetin önünün alınabileceğini düşünen erkek diş hekimlerinin oranı \%96.2 ( $\mathrm{n}=25)$ iken, bu oranın kadın diş hekimleri arasında \%80 (n=32) düzeyinde olduğu görüldü.

İş yerinde uğradığ kayette bulunduğu, bunlardan 17'sinin (\%48.6) yaşadığı şiddet olayı ile ilgili hiçbir işlem yapılmadığını ve 10 'ununda da (\%28.6) saldırgana sözel uyarı yapıldığını bildirdiği görüldü (Tablo 4).

Anketi cevaplandıran diş hekimleri; saldırganların şiddete başvurma sebepleri arasında, en çok \%30.5 oranında eğitim seviyesi düşüklüğünü, ikinci sırada ise \%28.3 ile sağlık politikalarını sebep olarak belirtmişlerdir (Tablo 5). 
Tablo 4. Şikayet durumunda izlenen yol.

\begin{tabular}{|l|l|l|}
\hline $\begin{array}{l}\text { Yaşanan şiddet olayları ile } \\
\text { ilgili izlenen yollar* }\end{array}$ & Sayı (n) & $\begin{array}{l}\text { Yüzde } \\
\text { (\%) }\end{array}$ \\
\hline $\begin{array}{l}\text { Sonuç alınamayacağı düşünce- } \\
\text { si ile şikayette bulunulmadı }\end{array}$ & 17 & 48,6 \\
\hline Sözel uyarı yapıldı & 10 & 28,6 \\
\hline $\begin{array}{l}\text { Olayla ilgili hukuksal süreç } \\
\text { başlatıldı }\end{array}$ & 3 & 8,6 \\
\hline Polis olaya dahil oldu & 1 & 2,8 \\
\hline Diğer & 4 & 11,4 \\
\hline Toplam & 35 & 100,0 \\
\hline
\end{tabular}

* Bu soruya birden fazla yanıt verildiği için sayı, şikayette bulunan kişi $(\mathrm{n}=32)$ sayısından fazladır.

Tablo 5. "Sizce sağlık alanında şiddete başvurulma nedenleri nelerdir?" anket sorusuna verilen cevapların dağılımı.

\begin{tabular}{|l|l|l|}
\hline Şiddete başvurma nedenleri* & Sayı (n) & Yüzde (\%) \\
\hline Eğitim seviyesi düşüklüğü & 54 & 30,5 \\
\hline Sağlık politikaları & 50 & 28,3 \\
\hline Medyada sağlık karşııı yayınlar & 28 & 15,8 \\
\hline $\begin{array}{l}\text { İhmal ve tedavi memnuniyet- } \\
\text { sizliği }\end{array}$ & 26 & 14,7 \\
\hline Kurum yetersizliği & 13 & 7,3 \\
\hline Diğer & 6 & 3,4 \\
\hline Toplam & 177 & 100,0 \\
\hline
\end{tabular}

* Bu soruya birden fazla yanıt verildiği için sayı, ankete katılan kişi sayısından fazladır.

Katılımcılar sağlık çalışanlarına yönelik şiddetin önlenebilmesi için en sık sağlık politikalarının düzenlenmesi (\%26.7) ve halka eğitim verilmesi (\%24.5) gerekliliği yönünde görüş bildirmişlerdir (Tablo 6).

\section{Tartışma}

Sağlik alanında başta stres ve yoğunluğun fazla olduğu bölümler olmak üzere şiddet yoğun olarak yaşanmaktadır (5-7,9-11). Bu çalışmada, kamuda çalışan diş hekimlerinin iş yerlerinde karşılaştıkları şiddet ele alınmıştır. Hedef kitlenin \%4.34'üne ulaşıldı ve bu sayı istatistiksel olarak yeterli bulundu.

Çalışmaya katılan diş hekimlerinin $\% 48.5$ 'i meslek hayatları boyunca en az bir kez, bunların da \%65.6'sı son bir yılda en az bir defa şiddete maruz kaldıklarını belirtti. Erbaycuhazırladığı tezsiz yüksek lisans projesinde, sağlık alanında şiddet ile ilgili çalışmaların sıklıkla hastaneler ve 112 acil sağlık hizmetleri göz önünde bulundurularak gerçekleştirildiğini belirterek, Zonguldak’ta ağız-diş sağ-
Tablo 6. "Sizce sağlık çalı̧̧anlarına yönelik şiddetin önlenmesi için neler yapılabilir?" anket sorusuna verilen cevapların dağılımı.

\begin{tabular}{|l|l|l|}
\hline $\begin{array}{l}\text { Sağlıkta şiddetin önlenmesi } \\
\text { için yapılabilecekler* }\end{array}$ & Sayı (n) & Yüzde (\%) \\
\hline Sağlık politikaları düzenlenmeli & 54 & 26,7 \\
\hline Halka eğitim verilmeli & 50 & 24,5 \\
\hline Hukuki tedbirler arttırılmalı & 40 & 19,6 \\
\hline Medya yayınları denetlenmeli & 33 & 16,1 \\
\hline Güvenlik tedbirleri arttırılmalı & 24 & 11,7 \\
\hline Diğer & 3 & 1,4 \\
\hline Toplam & 202 & 100,0 \\
\hline
\end{tabular}

* Bu soruya birden fazla yanıt verildiği için sayı, ankete katılan kişi sayısından fazladır.

lığı merkezi sağlık çalışanları ile yaptı̆̆ çalışmasında çalışanların \% 40.4'ünün kurumlarında en az bir kez şiddete maruz kaldıklarını tespit etmiştir (12). Erbaycu sadece diş hekimleri ile bir çalışma yapmamışsa da, çalışmanın sadece ağız-diş sağlığ 1 hizmeti verilen bir yerde gerçekleştirilmesi nedeniyle diş hekimleri ile yaptığımız çalışmayla bu nedenle benzer bir sonuç verdiği düşünülmüştür. Ağız-diş sağlığı hizmeti dışında sağlık hizmeti veren sağlık kurumlarında yapılan çalışmalarda, iş yaşamları boyunca şiddete maruz kaldıklarını belirten sağlık personeli oranlarının daha yüksek olduğu görülmüştür $(11,13,14)$. $\mathrm{Bu}$ durum, sağlık alanında daha yoğun ve stres altında çalışılan birimlerde şiddetin daha fazla olduğunu düşündürmüştür. Sağlık hizmetlerinde acil servislerin şiddetin en yoğun görüldüğü yerler olarak belirtilmesi bu görüşümüzü desteklemektedir $(3,15)$. Bununla birlikte, İngiliz Diş Hekimleri Birliği’nin üç yıllık bir periyodu kapsayan çalışmasında diş hekimleri ve yardımcı personelin \%80'inin işyerinde şiddete uğradığı saptanmıştır (16). Sağlık hizmet alanı, hizmet alıcılarının hizmetten beklentilerinin yüksek olduğu bir alan olduğu için beklentilerin karşılanamaması, karşılanmasındaki aksaklıklar (müdahalenin gecikmesi, süreç hakkında bilgi verilmemesi vs.) ya da kişilerin ve/veya yakınlarının sağlık problemleri nedeniyle yaşadıkları semptomların (ağrı, kanama gibi) kaygı ve endişelerini arttırması, sağlık çalışanlarının bu kaygı ve endişeyi azaltmak adına yeterli zamanlarının olmaması, kimi zaman da bu konuda yatıştırıcı bir tavır sergilememeleri bunların yanında medyanın sağlık alanında şiddet ile ilgili olumsuz algı yaratan haberleri gibi durumlar bu alandaki şiddetin daha fazla olmasının nedenleri arasında düşünülmektedir.

Sağlık alanındaki şiddet hem yurtiçinde, hem de yurtdışındaki çalışmalarda, sözel şiddet olarak ön plana çıkmakta ve sıklıkla hasta ve hasta yakınları tarafından 
uygulandığı gözlenmektedir (6,7,12-14). Nijerya'da diş hekimleri ve yardımcıları ile yapılan bir anket çalışmasında da, bağırma ve korkutma şeklindeki sözel şiddetin en sık maruz kalınan şiddet türü olduğu ve en sık hastalar tarafından şiddetin uygulandığı saptanmıştır (6). Duygusal şiddet türlerinden biri olan sözel şiddet, bu çalışmada da diş hekimleri tarafindan en sık maruz kalınan ve tanık olunan şiddet türü olarak belirtilmiş olup, sözel şiddetin diğer şiddet türlerine de sıklıkla eşlik ettiği gözlenmiştir. Ayrıca diğer çalışmalara benzer şekilde şiddetin hasta ve hasta yakınları tarafından uygulandığı belirlenmiştir. Sağlık kurumlarında hastalıkların yol açtığı acı, ağrı ya da sıkıntılar nedeniyle korku, endişe ve kaygı düzeyleri en yüksek kişiler hastalar ve ikinci sırada da hasta yakınları olmaktadır (17).Bu nedenlerle, şiddete en sık başvuran kişilerin hasta ve hasta yakınları olduğu düşünülmüştür. Nijerya'da yapılan benzer bir çalışmada, uzun bekleme süreleri ve randevu iptallerinin şiddetin sebepleri arasında ilk sıralarda olduğu belirtilmiştir (6). Ülkeden ülkeye sağlık hizmetinin veriliş koşulları değişebileceğinden şiddet sebeplerinin de değişebileceği aşikardır.

$\mathrm{Bu}$ çalışmaya katılan diş hekimlerinin 1/3'ünden fazlası kendilerini işyerinde güvende hissetmediklerini belirtmişlerdir. Katılımcıların yaklaşık yarısının meslek hayatlarında en az bir kez şiddete maruz kalmaları, medyada sıklıkla sağlık alanında şiddet haberlerine rastlanması ve katılımcıların çok yüksek oranlarda toplumda ve çalışııları kurumlarda (sırasıyla \%95.5 - \%69.7) şiddetin arttığı yönündeki görüşlerinin diş hekimlerinin işyerinde kendilerini güvende hissetmemelerinde etkili faktörler arasında görülmüştür.

Yaşanan şiddet olayları ile ilgili izlenen yollar sorgulandığında verilen cevapların yaklaşık yarısının sonuç alınamayacağı düşüncesiyle şikayette bulunulmadı şeklinde olduğu görülmüş olup bu durumun şikayette bulunma oranını da olumsuz etkilediği düşünülmektedir.

Diş hekimleri, saldırganın şiddete başvurma nedenleri arasında eğitim seviyesinin düşüklüğü ve sağlık politikalarını saymış olup, önlem olarak da sağlık politikalarının düzenlenmesi ve halka eğitim verilmesinin iş yerinde şiddetin önlenmesi için yapılabilecekler arasında en sık belirtilen unsurlar olarak belirtmişlerdir. Elbette ki devletin sağlık alanında şiddetin önlenmesi adına gerekli tedbirleri alması kaliteli bir hizmet için en önemli adımlardan biridir. Bu bağlamda, sağlık alanındaki şiddet olaylarının artışı ve sağlık çalışanlarının güvenli ortamlarda, yüksek motivasyonla çalışmalarının sağlanması için Sağlık Bakanlığ 2011 yılında "Hasta ve Çalışan Güvenliğinin Sağlanmasına Dair Yönetmelik" ve 2012 yılında "Çalışan Güvenliğinin Sağlanması" ile ilgili bir genelge yayımlamıştır $(18,19)$. Akabinde 14 Mayıs 2012 tarihi itibariyle sağlık çalışanlarının yaşadıkları şiddet olaylarının etkili bir şekilde idare edilebilmesi için "Beyaz Kod" uygulaması başlatılmıştır. Ancak, sağlık hizmetinin içinde olan gerek hizmeti alan kişilerin gerekse de hizmeti veren kişilerin bu uygulamalardan haberdar olmasının etkinlik için önemli olduğu düşünülmektedir. Her ne kadar katılımcılar önlem olarak, sağlık politikalarının düzenlenmesi gerektiğini vurgulamışlarsa da -etkinliği ayrı bir tartışma konusu olmakla birlikte- iyileştirme adına yapılan uygulamalardan biri olan beyaz kod uygulamasından katılımcıların yaklaşık yarısının (\%45.5) haberinin olmadığı anlaşılmıştır. Anketin yapıldığ 1 tarih göz önünde bulundurulduğunda uygulamanın üzerinden iki yıl gibi bir süre geçmesine rağmen çalışmaya katılan diş hekimlerinin yaklaşık yarısının bu uygulamayı bilmemeleri çarpıcı bir sonuç olarak ortaya çıkmıştır.

\section{Sonuç}

Sağlık hizmeti bir ülkede verilen en önemli hizmetlerden biri olup, ağız-diş sağlığı konusu da önemli bir sağlık hizmetidir. Çalışma küçük bir grubun sağlıkta şiddet konusundaki görüşlerini yansıtmakla birlikte, diş hekimlerinin sağlık alanındaki şiddetten etkilendiğini göstermektedir. Her ülke kendi şartlarına göre sağlık hizmetinin en iyi şekilde yürütülmesi için sağlıkta şiddeti önlemeye yönelik etkili yöntemler geliştirmelidir.

$\mathrm{Bu}$ çalışma verileri Türkiye açısından bir ön çalışma olarak değerlendirilebilir. Bu konuda örneklem sayısının artırılması ve anket sorularının çeşitlendirilmesi suretiyle sorunun belirlenmesi ve çözümüne yönelik başka çalışmalar planlanabilir. Bunun için sağllk hizmetini veren ve alan kişilerin görüşlerini bir arada değerlendirecek çalışmaların yapılmasının önemli olduğunu düşünmekteyiz.

\section{Kaynaklar}

1. Krobath J. Saldırganlık ve şiddet tanımı. Empowering immigrant women to end violence [Internet]. [cited 2016 January 2]. Available from: http://www.omega-graz.at/ download/Mini\%20Manual_Turkish.pdf

2. Yıldız AN, Kaya M. İşyerinde şiddet. Toplum Hekimliği Bülteni 2009; 28: 1-6.

3. Martino VD, Musri M. Guidance for the prevention of stress and violence at the workplace, 1 st edn. Kuala Lumpur: Ministry of Human Resources Malaysia: Department of Occupational Safety and Health Malaysia; 2001.

4. Mohr SN, Shalat SL. Office and services workers. Rosenstock L, Cullen MR, Brodkin CA, Redlich CA, eds. Textbook of Clinical Occupational and Environmental Medicine. Elsevier Inc: British Library Cataloguing in Publication Data; 2005. p. 230.

5. International Labor Office. Framework guidelines for addressing workplace violence in the health sector. 1st edn. Geneva: International Labour Office; 2002. 
6. Azodo CC, Ezeja EB, Ehikhamenor EE. Occupational violence against dental professionals in southern Nigeria. Afr Health Sci 2011;11:486-92. Available from: http:// www.ajol.info/index.php/ahs/article/view/73420/62336

7. Khalef A. Is workplace violence inevitable? Baker J, ed. Violence at work. Geneva: International Labour Office; 2003. p.13.

8. Türk Diş Hekimleri Birliği 2013 yılı verileri [Internet]. [cited 2016 April 2]. http://www.tdb.org.tr/mwg-internal/ de5fs23hu73ds/progress?id=d3UD0bW7aw.

9. Kaya A, Karadayi B, Kolusayin O, Akan Aslan N, Oral G. Violence in the health sector and its properties: A questionnaire toward physician working in the emergency departments. JAEM 2014;13:124-30. doi: 10.5152/ jaem.2014.66587.

10. Yeşildal N. Sağlık hizmetlerinde iş kazaları ve şiddetin değerlendirilmesi. TSK Koruyucu Hekimlik Bülteni 2005;4:280-302.

11. Ayranci U, Yenilmez C, Balci Y, Kaptanoglu C. Identification of violence in Turkish health care settings. J Interpers Violence 2006;21(2):276-296. doi: $10.1177 / 0886260505282565$

12. Erbaycu E. Sağlık kurumlarında çalışanların şiddet ile ilgili bilgi düzeyleri [tezsiz yüksek lisans projesi]. [Zonguldak]. Bülent Ecevit Üniversitesi; 2014.

13. Çamcı O, Kutlu Y. Kocaeli'nde sağlık çalışanlarına yönelik işyeri şiddetinin belirlenmesi. Psikiyatri Hemşireliği Dergisi 2011;2:9-16.

14. Adaş EB, Elbek O, Bakır K. Sağlık Sektöründe Şiddet Raporu-I. Türk Tabipleri Birliği Gaziantep-Kilis Tabip Odas1 [Internet]. [cited 2015 August 12]. Available from: http://www.ttb.org.tr/siddet/images/file/gaziantepsiddet.pdf

15. Pemberton MN, Atherton GJ, Thornhill MH. Violence and aggression at work. Br Dent J 2000; 189: 409-10. doi:10.1038/sj.bdj.4800785

16. Survey into violence and abuse against general dental practitioners and their staff. London: British Dental Association; 1997.

17. Oral G, Kaya A. Acil hizmetlerde sağlık personeline yönelik şiddet. In: Çetin G, Kaya A, editors. Hekimlik uygulamalarının adli tıbbi güncellemesi. İstanbul: İ.Ü. Cerrahpaşa Tıp Fakültesi Sürekli Tıp Eğitimi Etkinlikleri Sempozyum Dizisi; 2012. p. 86-96.

18. Hasta ve Çalışan Güvenliğinin Sağlanmasına Dair Yönetmelik, RG: 06.04.2011 tarih ve 27897say1l[[Internet]. [cited 2015 August 13]. Available from: https://www.sbn. gov.tr/icerikdosyalar/316182824_hcgyonetmelik.pdf

19. T.C. Sağlık Bakanlığı Sağlık Hizmetleri Genel Müdürlüğü'nün 14.05.2012 tarihli Çalışan Güvenliğinin Sağlanması konulu Genelge (2012/23) [Internet]. [cited 2015 August 13]. Available from: http://www.beyazkod. saglik.gov.tr/Dokumanlar/calisangenelgesi.pdf 